\title{
Mechanisms of Chronic Muscle Wasting and Dysfunction after an Intensive Care Unit Stay
}

Citation for published version (APA):

dos Santos, C., Hussain, S. N. A., Mathur, S., Picard, M., Herridge, M., Correa, J., Bain, A., Guo, Y., Advani, A., Advani, S. L., Tomlinson, G., Katzberg, H., Streutker, C. J., Cameron, J. I., Schols, A., Gosker, H. R., \& Batt, J. (2016). Mechanisms of Chronic Muscle Wasting and Dysfunction after an Intensive Care Unit Stay. American Journal of Respiratory and Critical Care Medicine, 194(7), 821-830.

https://doi.org/10.1164/rccm.201512-2344OC

Document status and date:

Published: 01/10/2016

DOI:

10.1164/rccm.201512-2344OC

Document Version:

Publisher's PDF, also known as Version of record

Document license:

Taverne

Please check the document version of this publication:

- A submitted manuscript is the version of the article upon submission and before peer-review. There can be important differences between the submitted version and the official published version of record.

People interested in the research are advised to contact the author for the final version of the publication, or visit the DOI to the publisher's website.

- The final author version and the galley proof are versions of the publication after peer review.

- The final published version features the final layout of the paper including the volume, issue and page numbers.

Link to publication

\footnotetext{
General rights rights.

- You may freely distribute the URL identifying the publication in the public portal. please follow below link for the End User Agreement:

www.umlib.nl/taverne-license

Take down policy

If you believe that this document breaches copyright please contact us at:

repository@maastrichtuniversity.nl

providing details and we will investigate your claim.
}

Copyright and moral rights for the publications made accessible in the public portal are retained by the authors and/or other copyright owners and it is a condition of accessing publications that users recognise and abide by the legal requirements associated with these

- Users may download and print one copy of any publication from the public portal for the purpose of private study or research.

- You may not further distribute the material or use it for any profit-making activity or commercial gain

If the publication is distributed under the terms of Article $25 \mathrm{fa}$ of the Dutch Copyright Act, indicated by the "Taverne" license above, 


\title{
Mechanisms of Chronic Muscle Wasting and Dysfunction after an Intensive Care Unit Stay A Pilot Study
}

\begin{abstract}
Claudia dos Santos ${ }^{1,2}$, Sabah N. A. Hussain ${ }^{3}$, Sunita Mathur ${ }^{4}$, Martin Picard ${ }^{5}$, Margaret Herridge ${ }^{2,6}$, Judy Correa ${ }^{1}$, Alexandra Bain ${ }^{7}$, Yeting Guo ${ }^{3}$, Andrew Advani ${ }^{1,8}$, Suzanne L. Advani ${ }^{1,8}$, George Tomlinson ${ }^{8}$, Hans Katzberg ${ }^{9}$, Catherine J. Streutker ${ }^{1,10}$, Jill I. Cameron ${ }^{11}$, Annemie Schols ${ }^{12}$, Harry R. Gosker ${ }^{12}$, and Jane Batt ${ }^{1,7}$; for the MEND ICU Group, the RECOVER Program Investigators, and the Canadian Critical Care Translational Biology Group

${ }^{1}$ Keenan Research Centre for Biomedical Science, St. Michael's Hospital, Toronto, Ontario, Canada; ${ }^{2}$ Division of Critical Care Medicine, Department of Medicine, ${ }^{4}$ Department of Physiotherapy, ${ }^{7}$ Division of Respirology, Department of Medicine, ${ }^{8}$ Department of Medicine, 9 Division of Neurology, Department of Medicine, ${ }^{10}$ Department of Laboratory Medicine and Pathobiology, and ${ }^{11}$ Department of Occupational Science and Occupational Therapy, University of Toronto, Toronto, Ontario, Canada; ${ }^{3}$ Department of Critical Care, McGill University Health Centre, and Meakins-Christie Laboratories, McGill University, Montreal, Quebec, Canada; ${ }^{5}$ Center for Mitochondrial and Epigenomic Medicine, Children's Hospital of Philadelphia and University of Pennsylvania, Philadelphia, Pennsylvania; ${ }^{6}$ Division of Critical Care Medicine, University Health Network, Toronto, Ontario, Canada; and ${ }^{12}$ Department of Respiratory Medicine, NUTRIM School of

Nutrition and Translational Research in Metabolism, Maastricht University Medical Centre, Maastricht, the Netherlands
\end{abstract}

\begin{abstract}
Rationale: Critical illness survivors often experience permanent functional disability due to intensive care unit (ICU)-acquired weakness. The mechanisms responsible for long-term weakness persistence versus resolution are unknown.
\end{abstract}

Objectives: To delineate cellular mechanisms underlying long-term weakness persistence in ICU survivors.

Methods: We conducted a nested, prospective study of critically ill patients mechanically ventilated for 7 days or longer. The patients were recruited from the RECOVER program and serially assessed over 6 months after ICU discharge. Twenty-seven of 82 patients consented to participate; 15 and 11 patients were assessed at 7 days and 6 months after ICU discharge, respectively.

Measurements and Main Results: We assessed motor functional capacity, quadriceps size, strength, and voluntary contractile capacity and performed electromyography, nerve conduction studies, and vastus lateralis biopsies for histologic, cellular, and molecular analyses. Strength and quadriceps cross-sectional areas were decreased 7 days after ICU discharge. Weakness persisted to 6 months and correlated with decreased function. Quadriceps atrophy resolved in 27\% patients at 6 months. Muscle mass reconstitution did not correlate with resolution of weakness, owing to persistent impaired voluntary contractile capacity. Compared with Day 7, increased ubiquitin-proteasome system-mediated muscle proteolysis, inflammation, and decreased mitochondrial content all normalized at 6 months. Autophagy markers were normal at 6 months. Patients with sustained atrophy had decreased muscle progenitor (satellite) cell content.

Conclusions: Long-term weakness in ICU survivors results from heterogeneous muscle pathophysiology with variable combinations of muscle atrophy and impaired contractile capacity. These findings are not explained by ongoing muscle proteolysis, inflammation, or diminished mitochondrial content. Sustained muscle atrophy is associated with decreased satellite cell content and compromised muscle regrowth, suggesting impaired regenerative capacity.

Keywords: muscle atrophy; ubiquitin-proteasome system; satellite cell; autophagy; mitochondria

(Received in original form December 4, 2015; accepted in final form March 10, 2016)

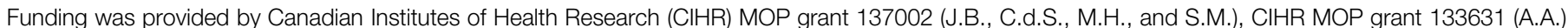

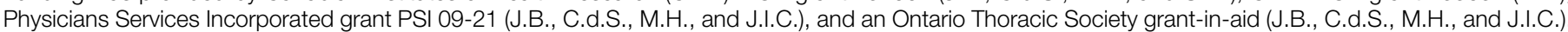

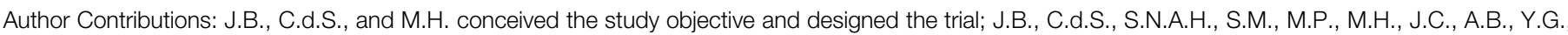
A.A., S.L.A., G.T., H.K., C.J.S., A.S., J.I.C., and H.R.G. performed experiments and/or data analysis and wrote and/or edited the manuscript.

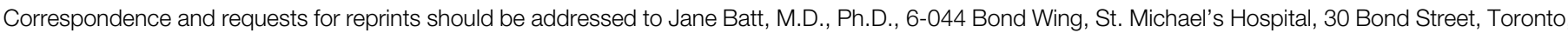
ON, M5B 1W8 Canada. E-mail: jane.batt@utoronto.ca

This article has an online supplement, which is accessible from this issue's table of contents at www.atsjournals.org

Am J Respir Crit Care Med Vol 194, Iss 7, pp 821-830, Oct 1, 2016

Copyright (C) 2016 by the American Thoracic Society

Originally Published in Press as DOI: 10.1164/rccm.201512-2344OC on April 8, 2016

Internet address: www.atsjournals.org 


\section{At a Glance Commentary}

\section{Scientific Knowledge on the}

Subject: Critical illness survivors often experience permanent functional disability due to intensive care unit (ICU)-acquired weakness. The mechanisms responsible for long-term weakness persistence versus resolution are unknown.

\section{What This Study Adds to the}

Field: We show that ICU-acquired weakness that persists long term in survivors of critical illness results from heterogeneous muscle pathophysiology with variable degrees of muscle atrophy and decreased voluntary contractile capacity. Following acute skeletal muscle proteolysis in the ICU, sustained muscle atrophy in the long term derives from impaired regrowth and is associated with decreased satellite cell content. This has critical implications for the development of treatment and rehabilitative strategies.
Individuals who survive critical illness experience functional disability that is evident in the intensive care unit (ICU) (1) and may persist for years after discharge $(2,3)$. Premorbid conditions, critical illness, prolonged immobilization, and complications of ICU care including mechanical ventilation contribute to muscle and nerve damage, referred to as ICU-acquired weakness (ICUAW) (4). In the short term, ICUAW is associated with failure to wean from the ventilator and increased in-hospital mortality $(1,5,6)$. ICUAW that persists for months to years following critical illness imparts functional disability and significantly impairs quality of life.

The mechanisms underlying the acute loss of muscle mass and function during critical illness have been investigated extensively over the past decade in both animal models and patients. Proteolytic degradation of muscle in combination with electrical silencing and excitationcontraction uncoupling all contribute to muscle dysfunction in the ICU during the acute phases of critical illness (7-9). Comprehensive longitudinal data concurrently assessing structural, functional, and molecular features of
ICUAW sustained long term in survivors of critical illness are, in contrast, completely lacking. Specifically, the cellular and molecular mechanisms responsible for recovery of strength versus the permanent persistence of weakness remain to be elucidated. This may have important implications for rehabilitation and management, and therapies based on the abnormalities observed early in the ICU may not apply to this long-term recovery phase. We hypothesized that a sustained failure to repair and regrow injured or atrophic muscles following critical illness underlies the pathogenesis of persistent ICUAW. To test this hypothesis, we quantified motor functional capacity, skeletal muscle size, strength and voluntary contractile capacity, and peripheral nerve function, and we performed muscle biopsies to evaluate cellular signaling and processes associated with muscle proteolysis and repair in critical illness survivors serially over the time at which functional recovery plateaus (6 mo) following discharge from the ICU. Some of the results of these studies have been reported previously in the form of an abstract (10).

Table 1. Patient Demographics

\begin{tabular}{|c|c|c|c|c|c|c|c|c|}
\hline Patient & Age (yr) & Sex & $\begin{array}{l}\operatorname{ICU} \\
\operatorname{LOS}(d)\end{array}$ & $\begin{array}{l}\text { APACHE II } \\
\text { Score }\end{array}$ & $\begin{array}{l}\text { DASI/Est Vo }{ }_{2} \max \\
(\mathrm{ml} / \mathrm{kg} / \mathrm{min})\end{array}$ & $\begin{array}{l}\text { Reason for ICU } \\
\text { Admission }\end{array}$ & Comorbidities & $\begin{array}{c}\text { Corticosteroid } \\
\text { Use }\end{array}$ \\
\hline 1 & 29 & $\mathrm{~F}$ & 9 & 22 & $58.2 / 34.6$ & Necrotizing fasciitis & None & No \\
\hline 2 & 78 & M & 9 & 30 & Missed & Gl perforation/rupture & $\begin{array}{l}\text { DM (complicated), } \\
\text { substance abuse }\end{array}$ & No \\
\hline 3 & 47 & M & 26 & 17 & $58.2 / 34.6$ & $\begin{array}{l}\text { Sepsis, non-urinary } \\
\text { tract origin }\end{array}$ & DM (uncomplicated) & Yes \\
\hline 4 & 69 & $\mathrm{~F}$ & 32 & 19 & $58.2 / 34.6$ & Renal failure & Hypertension & Yes \\
\hline 5 & 71 & M & 10 & 31 & $40.5 / 27.0$ & Cardiac arrest & $\begin{array}{l}\text { DM (uncomplicated), } \\
\text { hypertension }\end{array}$ & No \\
\hline 6 & 32 & M & 13 & 13 & $58.2 / 34.6$ & Head trauma & None & No \\
\hline 7 & 36 & $\mathrm{~F}$ & 52 & 13 & $58.2 / 34.6$ & Bacterial/viral pneumonia & None & Yes \\
\hline 8 & 23 & M & 19 & 10 & $58.2 / 34.6$ & Multiple trauma & None & No \\
\hline 9 & 66 & M & 14 & 22 & $39.5 / 26.6$ & $\begin{array}{l}\text { Sepsis of urinary } \\
\text { tract origin }\end{array}$ & COPD, hypertension & Yes \\
\hline 10 & 58 & $\mathrm{~F}$ & 14 & 29 & $50.2 / 31.2$ & Subarachnoid hemorrhage & DM (uncomplicated) & No \\
\hline 11 & 47 & $\mathrm{~F}$ & 88 & 31 & $58.2 / 34.6$ & Renal pulmonary syndrome & None & Yes \\
\hline 12 & 58 & $\mathrm{~F}$ & 51 & 34 & $28.0 / 21.6$ & Congestive heart failure & DM (complicated) & Yes \\
\hline 13 & 53 & M & 17 & 15 & $58.2 / 34.6$ & Multiple trauma & Hypertension & No \\
\hline 14 & 52 & M & 13 & 9 & $58.2 / 34.6$ & Subarachnoid hemorrhage & None & No \\
\hline 15 & 47 & $\mathrm{~F}$ & 19 & 30 & $58.2 / 34.6$ & Pulmonary embolectomy & Lymphoma & No \\
\hline
\end{tabular}

Definition of abbreviations: APACHE II = Acute Physiology and Chronic Health Evaluation II; COPD = chronic obstructive pulmonary disease; DASI/Est Vo 2 max = Duke Activity Status Index and corresponding estimated $\mathrm{V}_{2} \mathrm{max} ; \mathrm{DM}=$ diabetes mellitus; $\mathrm{GI}=$ gastrointestinal; ICU = intensive care unit; $L O S=$ length of stay . Demographics include preadmission comorbidities, estimates of preadmission physical functional capacity (DASI/est $\mathrm{Vo}_{2}$ max), severity of illness (APACHE II score), ICU LOS, corticosteroid use in the ICU and reason for admission. Sixty percent of patients (9 of 15) had preadmission comorbidities. Ninety-three percent of patients (14 of 15) self-reported the ability to undertake, at minimum, moderate exercise, and $67 \%$ (10 of 15$)$ were able to undertake strenuous activity preadmission, as indicated by their DASI scores. Forty-four percent of patients $(6$ of 15$)$ received corticosteroids within the ICU. No patients received neuromuscular blockade. Trauma patient 8 sustained left humerus, right femur, sacral ala, and left pubic rami fractures. Trauma patients 6 and 13 did not sustain extremity fractures (patient 6, facial fractures; patient 13, penetrating chest/abdominal trauma). 
A

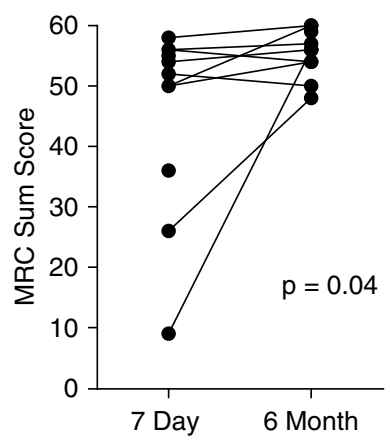

B

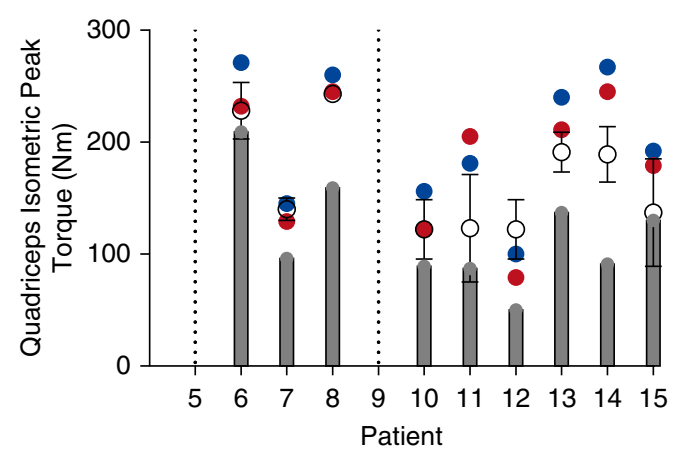

C
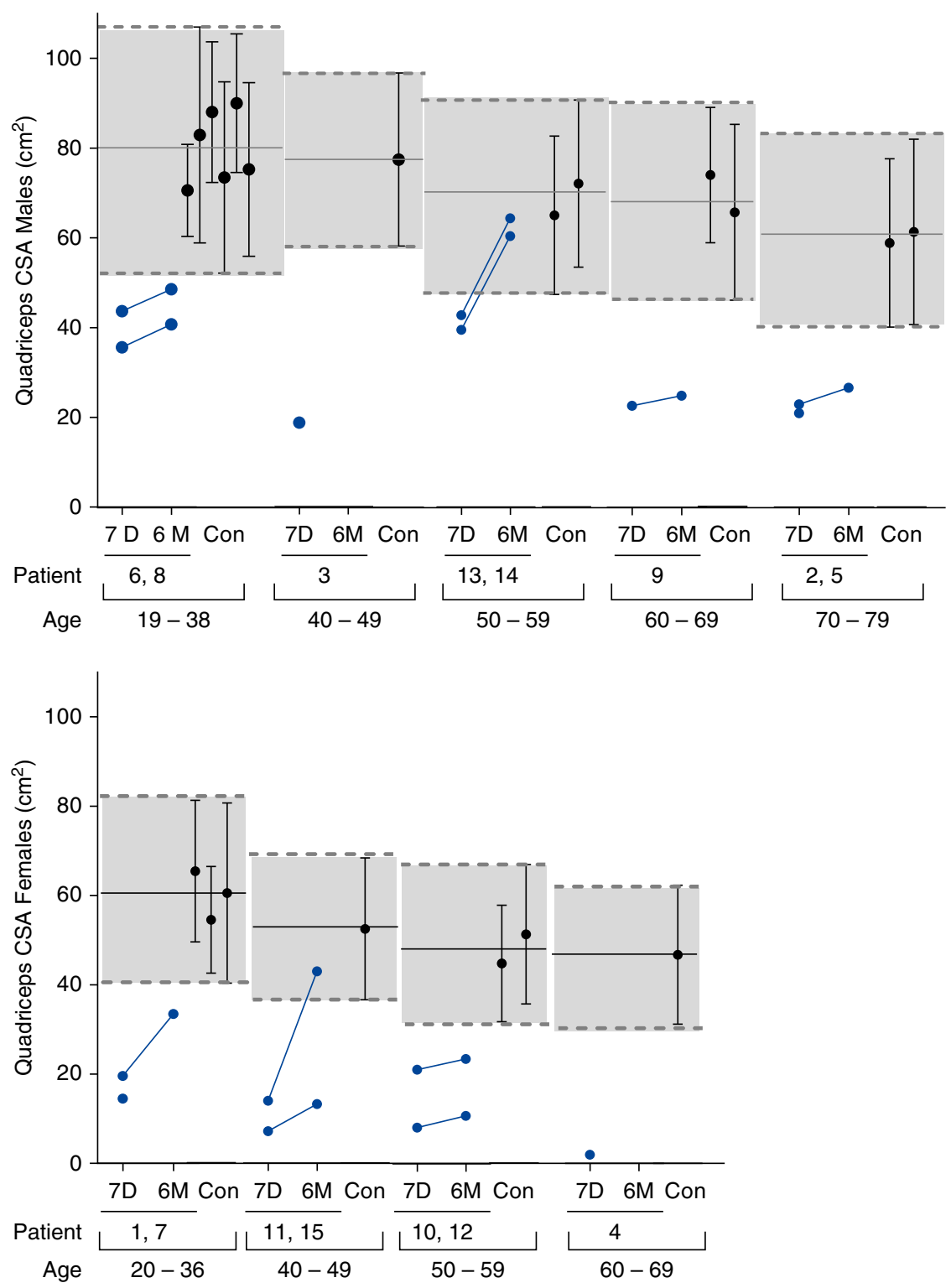

Figure 1. Persistent muscle weakness and atrophy 6 months after intensive care unit (ICU) discharge. (A) At 7 days after ICU discharge, patients demonstrated weakness, as indicated by a decreased Medical Research Council (MRC) Sum Score (13 of 13 patients), which improved

\section{Methods}

\section{Study Design}

We conducted a nested prospective study of patients recruited from the RECOVER Program, a multicenter, prospective longitudinal study evaluating functional outcomes in critically ill patients following prolonged mechanical ventilation over a 1-year period after ICU discharge (see online supplement for details). Individuals mechanically ventilated for a minimum of 1 week due to critical illness were recruited from three ICUs (two medical-surgical ICUs and one trauma ICU) in Toronto, Ontario, Canada, between September 2010 and April 2013. Informed consent was obtained from the participants, and the study protocol was approved by the research ethics boards of all participating institutions. For molecular and cellular analyses, banked muscle biopsy specimens previously collected from consenting healthy individuals were used for comparison purposes (see Table E1 in the online supplement). Patient assessments were conducted at 7 days and 6 months after ICU discharge. The greatest incremental improvement in physical function is known to occur within the first 6 months after ICU discharge and subsequently plateaus $(11,12)$. We reasoned that the selected post-ICU time points would provide muscle undergoing maximal repair (7 d) and muscle nearing completion of its maximal recovery (6 mo). Details on inclusion and exclusion criteria and all clinical evaluation tools and experimental protocols are included in the online supplement.

\section{Patient Recruitment, Demographics, and Severity of IIIness}

We obtained consent from 27 of 82 eligible patients, 15 and subsequently 11 of whom completed 7-day and 6-month follow-up assessments, respectively (Figure E1). The participants' baseline demographics are presented in Table 1. Study patients were representative of the ICU population undergoing prolonged mechanical ventilation (>1 wk) for critical illness (Table E2).

\section{Outcome Measures of Physical Functioning, Strength, and Muscle Mass}

Physical functional capacity was determined using the 6-minute walk distance and the 
Functional Independence Measure motor subscore. Global muscle strength was ascertained by using the Medical Research Council Sum Score. The quadriceps isometric peak torque was measured from maximal voluntary contractions using a Biodex System 4 dynamometer (Biodex Medical Systems, Shirley, NY). The cross-sectional area (CSA) of the quadriceps at its midsection was determined by computed tomography. Muscle specific force (voluntary contractile capacity) was calculated by normalizing quadriceps isometric peak torque to CSA. Electromyography (EMG) and nerve conduction studies were performed to assess neuropathy and myopathy. All testing was conducted at 7 days and 6 months after ICU discharge, with the exception of the Biodex dynamometer measurements (conducted solely at $6 \mathrm{mo}$ ).

\section{Muscle Biopsy}

Percutaneous biopsies of the vastus lateralis muscle were obtained from participants under local anesthetic at 7 days and 6 months after ICU discharge.

\section{Molecular Analysis \\ Muscle fiber CSA, ubiquitin-proteasome system (UPS) activity, autophagy, satellite cell content, vascularity, mitochondrial content, and presence or absence of an inflammatory infiltrate were assessed by a combination of Western blot analyses, $20 \mathrm{~S}$ proteasome activity measurements, immunohistochemistry, and electron microscopic imaging and analyses.}

\section{Statistical Analyses}

Continuous data are presented as the mean $( \pm \mathrm{SD})$. Nonnormally distributed discrete data are presented as the median (25th and 75th percentile) values. Comparisons between cohorts were conducted with oneway analysis of variance or the KruskalWallis test and post hoc analyses.

Correlations between outcome measures were determined by calculating Pearson or Spearman correlation coefficients. Statistical significance was assumed if $P$ value was less than 0.05 . All analyses were conducted with GraphPad Prism 6 software (GraphPad Software, La Jolla, CA).

\section{Results}

\section{Persistent Weakness 6 Months after ICU Discharge Correlated with Sustained Physical Functional Impairment}

Strength was decreased 7 days after ICU discharge and, while significantly improved by 6 months, did not normalize in the majority of patients (Figures 1A and 1B). Persistent weakness at 6 months correlated with physical functional impairment as assessed using the Functional Independence Measure motor subscore (Figures E2A, $\mathrm{E} 2 \mathrm{C}$, and $\mathrm{E} 2 \mathrm{D}$ ) and 6-minute walk distance (Figures E2B, E2E, and E2F).

\section{Muscle Atrophy Was Sustained in the Majority of Patients 6 Months after ICU Discharge}

All patients demonstrated significant quadriceps wasting 7 days following ICU discharge when compared with published age- and sex-matched, population-based norms (13-21) (Figure 1C). Quadriceps CSA was increased in all patients at 6 months, but there was significant variability in the extent of muscle regrowth, ranging from minimal $\left(\triangle \mathrm{CSA}<3 \mathrm{~cm}^{2}\right.$; patients 9,10 , and 12$)$ to substantial regrowth $\left(\triangle \mathrm{CSA}>21 \mathrm{~cm}^{2}\right.$; patients 13-15). Assuming that a quadriceps CSA that falls off the $95 \%$ confidence intervals for an age- and sex-matched healthy population can be deemed abnormal, $73 \%$ of patients ( 8 of 11 ) demonstrated persistent quadriceps atrophy 6 months following ICU discharge. Myofiber type-specific CSA was similarly decreased at 7 days after ICU discharge, persisting in $70 \%$ of patients (7 of 10) at 6 months (Figure E3).

\section{Muscle Mass Did Not Correlate with Strength}

Six months following ICU discharge, there was no significant correlation between quadriceps size and strength (Figure 2A). The three patients (27\%) whose quadriceps size normalized all showed persistent weakness due to decreased quadriceps voluntary contractile capacity, as determined by the muscle specific force (isometric peak torque normalized to the muscle CSA) (Figure 2B). Overall, patients with significant weakness demonstrated marked variation in the underlying muscle pathophysiologic processes, atrophy versus impaired voluntary contractile capacity, at 6 months following critical illness (Figure 2C).

\section{Electrophysiologic Testing Detected Persistent Myopathy at 6 Months} At 7 days after discharge, EMG and nerve conduction studies showed electrophysiologic evidence of myopathy and neuropathy in 79\% (11 of 14) and 36\% (5 of 14) of patients, respectively (Table E3). Myopathy detected by EMG persisted in $38 \%$ ( 3 of 8 ) of patients tested at 6 months post-ICU discharge, but neuropathy remained in only one of eight patients; that individual had complicated diabetes and also demonstrated myopathy. At 6 months following ICU discharge, patients with electrophysiologic evidence of myopathy were weaker than those without

Figure 1. (Continued). significantly but did not normalize (i.e., achievement of a score of 60 ) at 6 months in $82 \%$ of patients (9 of 11). Patient 8 did not undergo 7-day testing, owing to extremity fractures, and patient 5 was missed. (B) Similarly, 6 months after ICU discharge, patients demonstrated decreased quadriceps isometric peak torque (gray bars) compared with their predicted peak torque (as determined by using predictive formulae derived by Gosselink and colleagues (52) [red circles] or Harbo and colleagues (53) [blue circles]) or compared with age-identical and sex-matched quadriceps peak torque norms for healthy persons (open circles; mean peak torque \pm SD, derived at the University of Toronto Muscle Function and Performance Laboratory). Testing of patient 8 was conducted on the left quadriceps owing to his previous right femur fracture. Patients 5 and 9 declined testing (dotted lines). (C) One hundred percent of patients (15 of 15; blue circles) demonstrated muscle wasting, as determined by computed tomographic measurement of the quadriceps muscle cross-sectional area (CSA), at 7 days after ICU discharge (7D) compared with population-based, age- and sex-matched norms for healthy persons (Con; black circles are published quadriceps CSA means $\pm 95 \%$ confidence intervals [13-21]). Quadriceps CSA increased in all patients 6 months $(6 \mathrm{M})$ following ICU discharge, but only $27 \%$ of patients (patients 13-15) normalized quadriceps size (i.e., fell within $95 \%$ confidence interval). Patients 5-12 demonstrated persistent quadriceps atrophy. Patients 1-4 did not complete the 6-month assessments. The left quadriceps CSA of patient 8 was measured at both time points. 


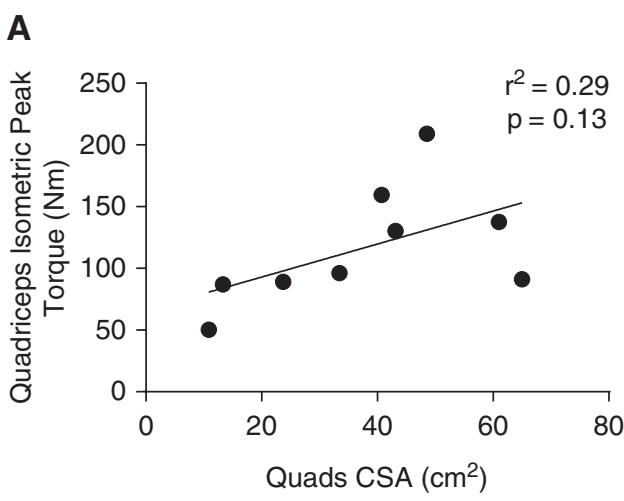

B
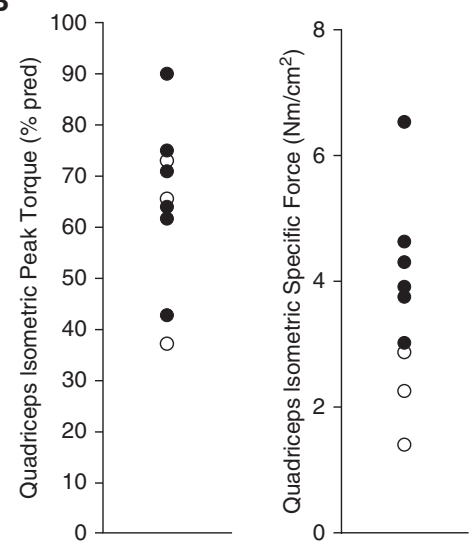

C

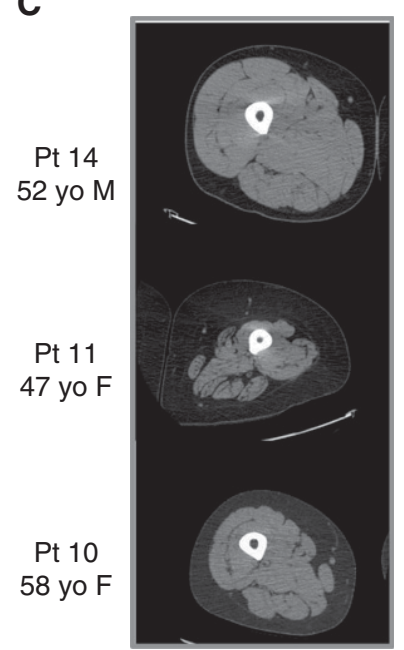

\begin{tabular}{cccc}
$\begin{array}{c}\text { Quads Torque } \\
(\% \text { pred })\end{array}$ & $\begin{array}{c}\text { Quads Specific } \\
\text { Force }\left(\mathrm{Nm} / \mathrm{cm}^{2}\right)\end{array}$ & $\begin{array}{c}\text { Quads CSA } \\
\left(\mathrm{cm}^{2}\right)\end{array}$ & $\begin{array}{c}\text { Quads } \triangle \mathrm{CSA} \\
\left(\mathrm{cm}^{2}\right)\end{array}$ \\
37.2 & 1.4 & 65.0 & 21.8 \\
\hline
\end{tabular}

42.8

6.5

13.3

6.1

Figure 2. Dissociation between muscle mass reconstitution and weakness resolution in intensive care unit (ICU) survivors. (A) There was no significant correlation between quadriceps isometric peak torque and quadriceps cross-sectional area (CSA) 6 months following ICU discharge. (B) Percent predicted (\% pred) quadriceps isometric peak torque (as determined using the Gosselink equation [52]) was decreased both in patients with persistent muscle atrophy at 6 months (solid circles) and in patients who reconstituted quadriceps CSA (open circles). Voluntary quadriceps contractile capacity, as determined by the quadriceps specific force of contraction (quadriceps peak torque $[\mathrm{Nm}]$ /quadriceps CSA $\left[\mathrm{cm}^{2}\right]$ ), was actually lowest in patients who reconstituted quadriceps size (open circles). (C) Representative thigh computed tomographic scans obtained 6 months post-ICU discharge demonstrated sustained weakness resulting from markedly different degrees of muscle atrophy versus impaired contractile capacity. Patient 14 normalized quadriceps size at 6 months with substantial muscle regrowth ( $\triangle \mathrm{CSA}$ ) but remained weak owing to low quadriceps specific force of contraction. Patients 10 and 11 remained weak owing to persistent muscle wasting, despite a higher muscle specific force of contraction $(\triangle \mathrm{CSA}=$ quadriceps CSA at $6 \mathrm{mo}-\mathrm{CSA}$ at $7 \mathrm{~d})$. $\mathrm{Pt}=$ patient.

it, as determined by the percent predicted quadriceps peak torque $(54.8 \pm 6.6 \%$ vs. $77.5 \pm 6.6 \%$, respectively; $P=0.07)$ and Medical Research Council Sum Score (51.5 \pm 1.5 vs. $57.6 \pm 0.8$, respectively; $P<0.05)$.

\section{Quadriceps Inflammatory Infiltrate} Seven days following ICU discharge, an inflammatory infiltrate of leukocytes was always present, but it resolved by 6 months in all patients (Figure E4).

\section{Quadriceps Wasting at 6 Months Was Not Associated with UPS-mediated Muscle Proteolysis}

Qualitative assessment of electron revealed sarcomere destruction in $100 \%$ of patients (15 of 15$)$ at 7 days after ICU microscopic sections of the vastus lateralis discharge, with resolution noted in all patients at 6 months (Figure E5). Increased UPS-mediated proteolysis was evident in the vastus lateralis 7 days after ICU discharge, as determined by measurement of $20 \mathrm{~S}$ proteasome activity and total ubiquitinated protein levels (Figures 3 and E6). However, by 6 months, UPS activation decreased in patients (with and without sustained quadriceps atrophy) to levels comparable to those of healthy individuals.

\section{Altered Autophagy Was Not Evident in Atrophic Quadriceps}

To assess autophagy engagement, we measured expression of three key autophagy coregulatory proteins (beclin 1 and VPS34, which are involved in autophagosome formation, and Bnip3, which is involved in selective targeting of mitochondria by autophagosomes) in addition to determining the extent of $\mathrm{LC} 3 \mathrm{~B}$ lipidation, which indicates enhanced LC3B mobilization to autophagosome membranes (Figures E7 and E8). Two measures-LC3 lipidation and Bnip3 expression-remained consistent across serial muscle biopsies from patients 7 days and 6 months after ICU discharge, as well as from healthy individuals. VPS34 was significantly increased at 7 days after discharge but fell to levels in keeping with those of healthy individuals at 6 months, whereas beclin 1 was increased at both 7 days and 6 months after discharge, regardless of the presence or absence of muscle atrophy at either time point. The variability among assays at 7 days after discharge precluded conclusions regarding differences between patients and healthy individuals. By 6 months, however, there were no differences in the majority of autophagy markers, with the exception of increased beclin 1 levels in the patients, but this was not associated with the development of sustained atrophy.

\section{Decreased Satellite Cell Content Associated with Persistent Muscle Atrophy}

Vastus lateralis satellite cell content was decreased at 7 days and 6 months after ICU discharge in patients who had the smallest incremental increases in quadriceps CSA and sustained muscle 
A
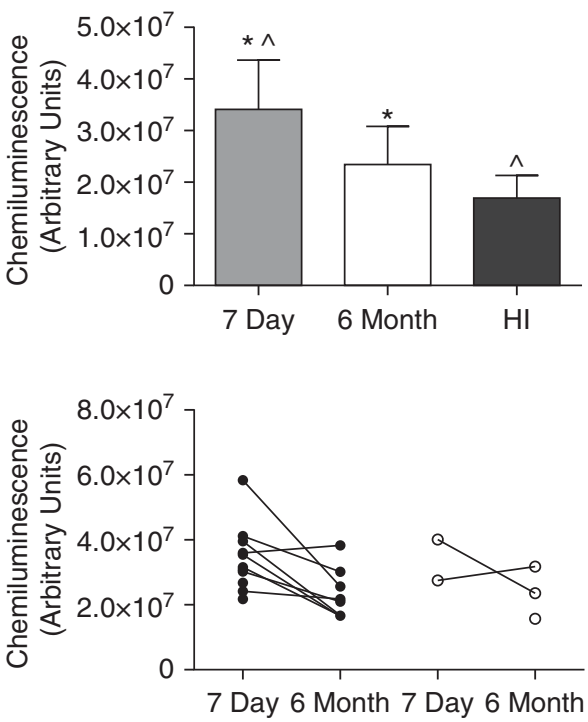

Atrophic Quads Normal Quads
B
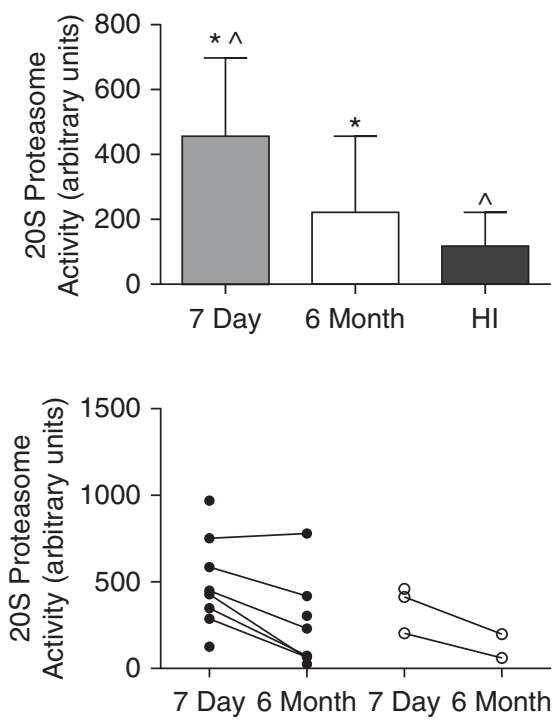

Atrophic Quads Normal Quads

Figure 3. Ubiquitin-mediated proteolysis transiently increased in quadriceps muscle 7 days after intensive care unit (ICU) discharge. (A) Western blotting for ubiquitin demonstrates significantly increased ubiquitination of muscle total proteins in patients at 7 days after ICU discharge, but this decreased at 6 months after ICU discharge to levels comparable with those of healthy individuals $(\mathrm{HI})$ $(n=6)$. There was no difference in the extent of ubiquitination between those patients with persistent atrophy (patients 5-12; atrophic quads) and those patients whose quadriceps cross-sectional area (CSA) normalized (patients 13-15; normal quads). Ubiquitin Western blots are shown in Figure E6. The left vastus lateralis of patient 8 was biopsied because of right femur fracture. (B) 205 proteasome activity was significantly increased at 7 days after ICU discharge, but this decreased in all patients at 6 months after ICU discharge to levels comparable with those of healthy individuals $(n=3)$. There was no difference in proteasome activity between patients whose muscle CSA normalized and those whose did not. Bar graphs show mean $\pm \mathrm{SD}$. ${ }^{* \wedge} P<0.05$.

wasting at 6 months (Figures 4 and E9). Muscle vascularization (capillary-tomyofiber ratio) correlated with the satellite cell content (Figure E10).

\section{Quadriceps Mitochondrial Content Normalized Despite Sustained Weakness}

Vastus lateralis mitochondrial content was significantly decreased at 7 days after ICU discharge but was increased at 6 months after ICU discharge and was similar to that of healthy individuals (Figure E11). No differences were detected between patients and healthy individuals in mitochondrial size at either time point following ICU discharge (Figure E11). Bioenergetic status of the cell as determined by the ratio of phosphorylated AMP-activated protein kinase to AMP-activated protein kinase was not changed between the groups at either 7 days or 6 months after ICU discharge $(1.41 \pm 0.99$ and $2.30 \pm 1.98$, respectively) and in healthy individuals $(1.90 \pm 2.00 ; P=0.45$ by analysis of variance).

\section{Discussion}

In this cohort of critical illness survivors, we demonstrate that persistent ICUAW 6 months following resolution of critical illness is associated with a heterogeneous muscle pathophysiology. Long-term weakness derives from markedly variable combinations of muscle atrophy and decreased muscle specific force (voluntary contractile capacity), which occurs with intact muscle ultrastructure and nerve function. In contrast to what is known about the development of acute ICUAW during critical illness, we show that persistent weakness at 6 months cannot be explained by ongoing UPS-mediated proteolysis, inflammation, muscle autophagy, or changes in mitochondrial structure or content. Instead, for those with persistent muscle wasting 6 months post-ICU discharge, quadriceps regrowth is compromised and associated with a lower satellite cell content.

Muscle wasting during critical illness can be severe and in excess of what is expected solely with inactivity $(22,23)$ or systemic illness (24-26). It occurs early and rapidly during the first week of critical illness and is more profound among those with multiorgan failure (7). Increased muscle proteolysis relative to protein synthesis is essential for the development of muscle atrophy $(27,28)$. Previous studies demonstrated that increased protein breakdown, in excess of synthesis, maintains an overall catabolic state in the muscle of critically ill patients $(7,29)$. UPS-mediated proteolysis is the predominant system that induces loss of muscle mass $(27,28)$. Increased expression of proteasome components and increased proteasome activity have previously been reported in the atrophying muscle of the critically ill patient (30-32). Alternative and indirect assessment of UPS engagement by evaluation of expression levels of key regulatory signaling proteins or their transcripts has yielded inconsistent results $(7,29,33)$, likely due in part to variable sampling times during acute muscle wasting within the ICU and the complexity of temporal and cellular spatial interplay of these signaling proteins in regulating muscle mass. Whole-system principal component analysis has been used recently in an attempt to deal with these complexities of molecular signaling regulating muscle breakdown, and it revealed patterns of intracellular signaling that supported increased proteolysis and depressed protein synthesis (7). While our study did not address the mechanisms of muscle wasting during critical illness, we did note sarcomeric destruction and increased UPS activation in our patient cohort at 7 days after ICU discharge, suggesting we were seeing residual UPS-mediated proteolysis that had been induced by critical illness during the ICU stay.

In contrast, we were unable to convincingly demonstrate altered autophagy in atrophied muscle following resolution of critical illness. Autophagy clears damaged and unwanted cellular components, and maintenance of 
A

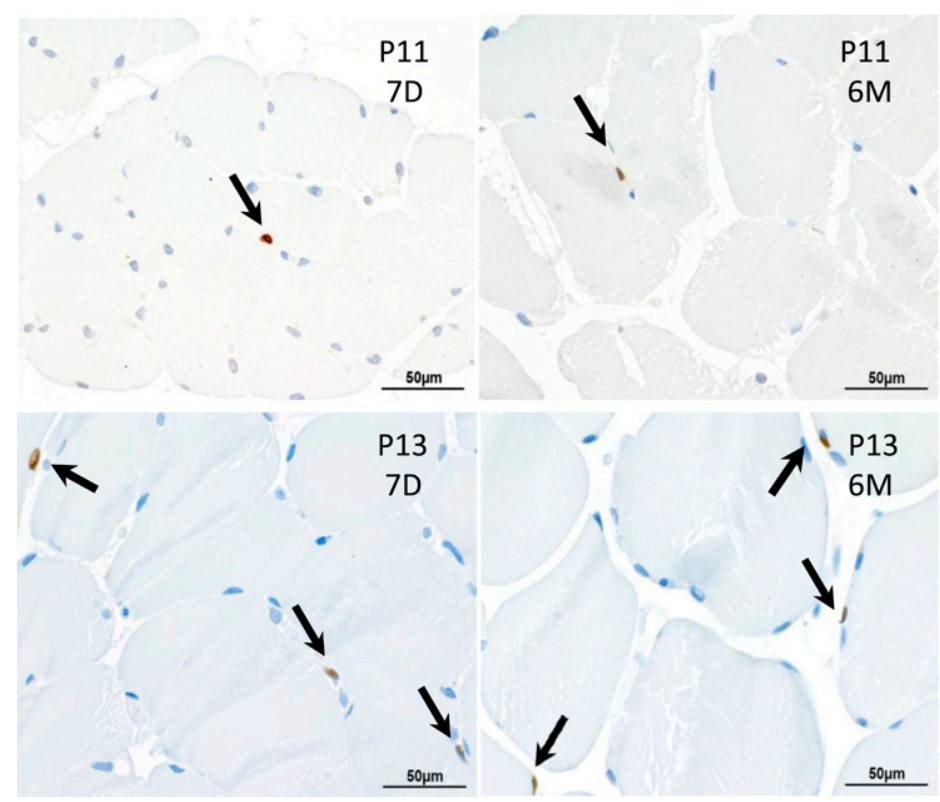

B

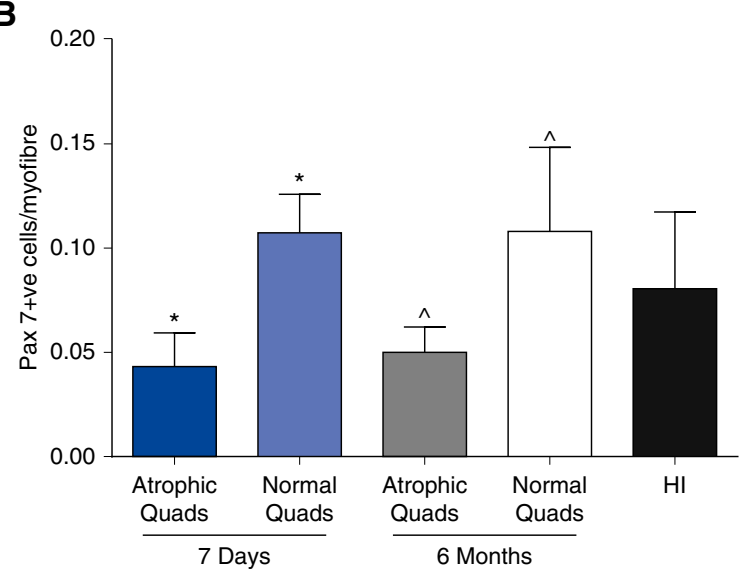

C

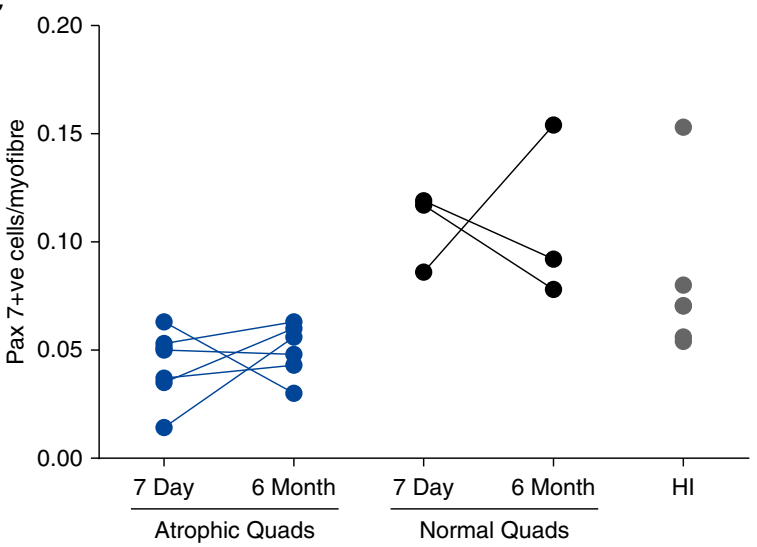

Figure 4. Vastus lateralis satellite cell content was decreased in patients with persistent atrophy compared with those whose cross-sectional area (CSA) normalized at 6 months after intensive care unit (ICU) discharge. (A) Histologic cross sections were immunostained for paired box gene 7 (Pax7) (brown staining, indicated by arrows), a marker of satellite cells. Representative images are shown for patient 11 (P11), who demonstrated persistent quadriceps atrophy at 6 months after ICU discharge, and patient 13 (P13), whose quadriceps CSA normalized. (B and $C$ ) Those patients with autophagic balance is critical to the preservation of healthy muscle mass. Excessive autophagy results in muscle catabolism, and impaired autophagy results in the accumulation of damaged muscle components and muscle degradation (28). Previous studies have demonstrated that autophagy contributes to muscle catabolism in the ICU $(34,35)$. If altered autophagy occurred in our patients, it may have happened early in the course of critical illness but had begun to abate by the time of our evaluation 7 days after ICU discharge.

We found that the parameters of muscle proteolysis normalized 6 months following resolution of critical illness, indicating that neither enhanced UPS activity nor altered autophagy can explain the sustained muscle atrophy seen in some critical illness survivors. We speculated that persistent atrophy must result from impaired muscle growth following its catabolism in the ICU. In young, healthy individuals, normalization of muscle mass following prolonged inactivity has been reported to occur within weeks of resuming ambulation. For example, men (aged $32 \pm$ $12 \mathrm{yr}$ ) subjected to bed rest for 17 weeks had normalized quadriceps, ankle extensor, and flexor mass within 5 weeks of ambulation (22). Muscles immobilized and/or inactive due to fracture or joint injury can demonstrate slower recovery rates, with rapid recovery early on but tapering as time passes. Researchers in some studies have reported near or complete recovery of mass by 10-24 weeks postinjury $(36,37)$, while others have demonstrated $20 \%$ loss of muscle $1-5$ years following lower limb trauma (38). While our patients were exposed to prolonged bed rest none, with one exception, had experienced lower limb fracture; in that individual, quadriceps CSA was measured on the contralateral leg. On the basis of these data, at 6 months we would expect our ICU population to have ultimately reconstituted their muscle mass to its final possible maximum or very close to it.

The corticosteroid administered to some of our patients may have contributed to the induction of acute muscle wasting while in the ICU, but the role of these agents in ICUAW remains unclear, with studies both suggesting and refuting an association $(8,39)$. In those studies suggesting an association, strength testing was often 
conducted in the absence of measurement of muscle mass, so the underlying contribution of wasting versus impaired contractility is unknown. Similarly, diabetes or chronic obstructive pulmonary disease, which in themselves can induce muscle wasting $(24,26)$, were comorbidities in four of our patients with sustained muscle atrophy; thus, these could also have played a contributory role. This information notwithstanding, two patients with no preadmission comorbidity and who did not receive corticosteroids demonstrated sustained muscle wasting 6 months after discharge, reiterating the capability of an episode of critical illness to cause enduring muscle compromise.

Following injury, muscle grows via hypertrophy of existing myofibers when structural and/or contractile proteins are synthesized and via regeneration where muscle progenitor satellite cells proliferate and differentiate to fuse to become mature muscle (40). While satellite cells are not required for the hypertrophic response of healthy muscle to mechanical load, or for the regrowth of muscle atrophied simply by immobility and/or unloading (41), they are essential for the regeneration of injured muscle (42-44). Decreased satellite cell content also contributes to the sarcopenia of aging (45). In our cohort, patients who had only a small increment in muscle growth and whose quadriceps CSA failed to normalize over time had a lower quadriceps satellite cell content compared with those patients who recovered muscle mass. The diminished satellite cell content may play a causative role in poor muscle regrowth and sustained atrophy following critical illness. Of interest, we found that muscle capillarization correlated positively with satellite cell content, although we were unable to demonstrate a statistically significant difference in the capillary-tomyofiber ratio across groups. Myogenesis and angiogenesis are known to be linked, and a correlation between satellite cell and muscle capillary content has been reported previously (46).

Mitochondria are essential for muscle contractile function and maintenance of mass (47). Loss of muscle mitochondria is associated with poor outcomes in ICU patients, including increased mortality (48), and we demonstrate a decreased quadriceps mitochondrial content 7 days after ICU discharge. However, ICU survivors at 6 months displayed a normal muscle mitochondria population (content and size), suggesting that mitochondrial abnormalities are not responsible for the differential restoration of muscle mass or the variable muscle voluntary contractile capacity noted at 6 months after ICU discharge.

The mechanisms underlying the dissociation between restoration of muscle mass and persistent weakness induced by impaired contractile capacity noted in some of our patients remain to be elucidated. Other pathologic processes have similar effects on muscle biomechanics. In congestive heart failure, animal models suggest that observed dissociation between skeletal muscle mass and contractility results in part from excitation-contraction uncoupling induced by abnormalities in calcium sequestration (49). Weakness with aging is beyond what would be anticipated for loss in muscle mass, due in part to altered muscle quality with increased fat infiltration (50). Post-translational modifications of myofilament proteins such as phosphorylation, acetylation, and oxidation of myosin, troponins, and actin may also be involved in the dissociation between muscle mass restoration and poor muscle contractility (51). Our three patients whose muscle mass normalized but continued to be weak had only hypertension or previous lymphoma as a comorbidity, and they were not elderly, suggesting that critical illness itself and/or ICU-related therapies may induce permanent impairment of muscle contractile capacity independent of muscle mass reconstitution.

The discovery study presented is limited by the small number of patients assessed. While our recruitment was reasonable, with 27 of 82 eligible patients consenting, the attrition rate was high, given their illness severity, and we lost several patients in follow-up due to death, ICU repatriation, and medical complications precluding muscle biopsy. We acknowledge that the limited sample size may underpower some comparisons and will require further investigation with larger populations. The generalizability of our findings needs to be evaluated in other ICU cohorts. In addition, our banked biopsy specimens from healthy individuals were not tightly age and sex matched, which may have influenced our cellular and/or molecular analyses. We did not know the patients' preadmission quadriceps size; thus, our comparisons with control populations to ascertain the presence or absence of muscle wasting with critical illness may overestimate the degree of muscle loss. However, all patients selfreported at minimum a moderate activity level, with the majority capable of strenuous activity (as defined by the Duke Activity Index) before their ICU admission, suggesting that their preadmission muscle mass was not diminished. Similarly, we did not know the patients' preadmission quadriceps peak torque. However, the availability of validated predictive equations with which to determine an individual's expected torque provides a robust measure against which our outcomes can be compared.

We assessed only UPS- and autophagymediated proteolysis, but increased activity of calpains and caspases has been shown to induce muscle atrophy (27). While we found mitochondrial size and content to be normalized at 6 months, we did not evaluate mitochondrial function. Similarly, while we found a lower satellite cell content in the ICU patient with sustained muscle atrophy, we did not evaluate satellite cell proliferation or differentiation capacity to determine if the decrease was functionally relevant. We evaluated patients only to 6 months after ICU discharge because improvement in functional disability induced by critical illness has been reported to plateau between 6 months and 1 year $(11,12)$, suggesting that the observed muscle outcomes at 6 months are representative of the ultimate outcomes and not simply a delay in recovery.

In summary, we demonstrate that persistent muscle weakness following resolution of critical illness is associated with markedly variable combinations of muscle atrophy and impaired voluntary

Figure 4. (Continued). persistent quadriceps atrophy (atrophic quads; patients 5-12) at 6 months after ICU discharge demonstrated a decreased satellite cell population at both 7 days and 6 months after ICU discharge compared with patients whose quadriceps CSA normalized (normal quads; patients 13-15). Bar graphs show mean $\pm S D ;{ }^{*}{ }^{\wedge} P<0.05 . n=6$ healthy individuals $(H I) .+v e=$ positive. 
contractile capacity. While UPS-mediated muscle proteolysis contributes to atrophy of muscle during illness, it is not sustained over the long term. Persistent muscle wasting results instead from impaired muscle regrowth, potentially related to diminished regenerative capacity resulting from the loss of muscle progenitor satellite cells.

Our findings highlight that the biology of the muscle can be durably and even definitely altered by critical illness. The cellular signaling networks that regulate muscle mass and contractility are intertwined but can potentially be targeted individually, enabling pharmacologic therapies to be specifically directed to address atrophy, impaired contractility, or both. While targeting selective inhibition of UPS-mediated skeletal muscle proteolysis may be a potential therapeutic intervention for patients during the early proteolytic phase of ICUAW, this will not be appropriate in patients with prolonged nonresolving ICUAW, where the problem is compromised muscle growth and not ongoing enhanced proteolysis. Moreover, attempts at reconstitution of muscle mass may be less successful in those patients with satellite cell loss, relying predominantly on hypertrophic growth, nor may they mitigate weakness in those patients with decreased strength due to (massindependent) contractile dysfunction.

Author disclosures are available with the text of this article at www.atsjournals.org.

Acknowledgment: The authors gratefully acknowledge the administrative support of Orla Smith, Andrea Matte, Leslie Chu, Julia Lee, and Yoon Lee, as well as the technical expertise and assistance of Dawn Pearce, Roseane Nisenbaum, Sarah Sweetman, Vidya Beharry, Patricia Gali, Louis Zhou, and Xiolin He.

\section{References}

1. De Jonghe B, Sharshar T, Lefaucheur JP, Authier FJ, Durand-Zaleski I, Boussarsar M, Cerf C, Renaud E, Mesrati F, Carlet J, et al.; Groupe de Réflexion et d'Etude des Neuromyopathies en Réanimation. Paresis acquired in the intensive care unit: a prospective multicenter study. JAMA 2002;288:2859-2867.

2. Herridge MS. Legacy of intensive care unit-acquired weakness. Crit Care Med 2009;37:S457-S461.

3. Cuthbertson BH, Roughton S, Jenkinson D, MacLennan G, Vale L. Quality of life in the five years after intensive care: a cohort study. Crit Care 2010;14:R6.

4. Batt J, dos Santos CC, Cameron JI, Herridge MS. Intensive care unitacquired weakness: clinical phenotypes and molecular mechanisms. Am J Respir Crit Care Med 2013;187:238-246.

5. De Jonghe B, Bastuji-Garin S, Durand MC, Malissin I, Rodrigues P, Cerf C, Outin H, Sharshar T; Groupe de Réflexion et d'Etude des Neuromyopathies en Réanimation. Respiratory weakness is associated with limb weakness and delayed weaning in critical illness. Crit Care Med 2007;35:2007-2015.

6. Garnacho-Montero J, Amaya-Villar R, García-Garmendía JL, MadrazoOsuna J, Ortiz-Leyba C. Effect of critical illness polyneuropathy on the withdrawal from mechanical ventilation and the length of stay in septic patients. Crit Care Med 2005;33:349-354.

7. Puthucheary ZA, Rawal J, McPhail M, Connolly B, Ratnayake G, Chan P, Hopkinson NS, Phadke R, Dew T, Sidhu PS, et al. Acute skeletal muscle wasting in critical illness. JAMA 2013;310:1591-1600.

8. Hermans G, Van den Berghe G. Clinical review: intensive care unit acquired weakness. Crit Care 2015;19:274.

9. Friedrich O, Reid MB, Van den Berghe G, Vanhorebeek I, Hermans G, Rich MM, Larsson L. The sick and the weak: neuropathies/myopathies in the critically ill. Physiol Rev 2015;95:1025-1109.

10. Batt J, Hussain S, Mathur S, Picard M, Herridge MS, Tomlinson G, Correa J, Advani A, Bain A, Schols AMWJ, et al. MEND ICU - muscle injury and repair in critical illness survivors mechanically ventilated for over 7 days [abstract]. Am J Respir Crit Care Med 2015;191:A2288.

11. Herridge MS, Tansey CM, Matté A, Tomlinson G, Diaz-Granados N, Cooper A, Guest CB, Mazer CD, Mehta S, Stewart TE, et al.; Canadian Critical Care Trials Group. Functional disability 5 years after acute respiratory distress syndrome. N Engl J Med 2011;364: 1293-1304.

12. Herridge MS, Cheung AM, Tansey CM, Matte-Martyn A, Diaz-Granados N, Al-Saidi F, Cooper AB, Guest CB, Mazer CD, Mehta S, et al.; Canadian Critical Care Trials Group. One-year outcomes in survivors of the acute respiratory distress syndrome. N Engl J Med 2003;348:683-693.

13. Schantz P, Randall-Fox E, Hutchison W, Tydén A, Astrand PO. Muscle fibre type distribution, muscle cross-sectional area and maximal voluntary strength in humans. Acta Physiol Scand 1983;117:219-226.
14. Kasai T, Ishiguro N, Matsui $Y$, Harada A, Takemura M, Yuki A, Kato $Y$, Otsuka R, Ando F, Shimokata H. Sex- and age-related differences in mid-thigh composition and muscle quality determined by computed tomography in middle-aged and elderly Japanese. Geriatr Gerontol Int 2015;15:700-706.

15. Häkkinen K, Newton RU, Gordon SE, McCormick M, Volek JS, Nindl BC, Gotshalk LA, Campbell WW, Evans WJ, Häkkinen A, et al. Changes in muscle morphology, electromyographic activity, and force production characteristics during progressive strength training in young and older men. J Gerontol A Biol Sci Med Sci 1998;53: B415-B423.

16. Goodpaster BH, Carlson CL, Visser M, Kelley DE, Scherzinger A, Harris TB, Stamm E, Newman AB. Attenuation of skeletal muscle and strength in the elderly: the Health ABC Study. J Appl Physiol (1985) 2001;90:2157-2165.

17. Segal NA, Zimmerman MB, Brubaker M, Torner JC. Obesity and knee osteoarthritis are not associated with impaired quadriceps specific strength in adults. PM R 2011;3:314-323, quiz 323.

18. Maughan RJ, Watson JS, Weir J. Strength and cross-sectional area of human skeletal muscle. J Physiol 1983;338:37-49.

19. Young $A$, Stokes $M$, Crowe $M$. The size and strength of the quadriceps muscles of old and young men. Clin Physiol 1985;5:145-154.

20. Kanehisa H, Ikegawa S, Fukunaga T. Comparison of muscle crosssectional area and strength between untrained women and men. Eur J Appl Physiol Occup Physiol 1994;68:148-154.

21. Housh DJ, Housh TJ, Weir JP, Weir LL, Johnson GO, Stout JR. Anthropometric estimation of thigh muscle cross-sectional area Med Sci Sports Exerc 1995;27:784-791.

22. LeBlanc AD, Schneider VS, Evans HJ, Pientok C, Rowe R, Spector E. Regional changes in muscle mass following 17 weeks of bed rest. J Appl Physiol (1985) 1992;73:2172-2178.

23. Trappe TA, Burd NA, Louis ES, Lee GA, Trappe SW. Influence of concurrent exercise or nutrition countermeasures on thigh and calf muscle size and function during 60 days of bed rest in women. Acta Physiol (Oxf) 2007;191:147-159.

24. Guo Y, Gosker HR, Schols AM, Kapchinsky S, Bourbeau J, Sandri M, Jagoe RT, Debigaré R, Maltais F, Taivassalo T, et al. Autophagy in locomotor muscles of patients with chronic obstructive pulmonary disease. Am J Respir Crit Care Med 2013;188:1313-1320.

25. Batt J, Ahmed SS, Correa J, Bain A, Granton J. Skeletal muscle dysfunction in idiopathic pulmonary arterial hypertension. $\mathrm{Am} \mathrm{J}$ Respir Cell Mol Biol 2014;50:74-86.

26. Park SW, Goodpaster BH, Strotmeyer ES, Kuller LH, Broudeau R, Kammerer C, de Rekeneire N, Harris TB, Schwartz AV, Tylavsky FA, et al.; Health, Aging, and Body Composition Study. Accelerated loss of skeletal muscle strength in older adults with type 2 diabetes: the health, aging, and body composition study. Diabetes Care 2007;30: 1507-1512.

27. Bonaldo $P$, Sandri M. Cellular and molecular mechanisms of muscle atrophy. Dis Model Mech 2013;6:25-39. 
28. Sandri M. Protein breakdown in muscle wasting: role of autophagylysosome and ubiquitin-proteasome. Int J Biochem Cell Biol 2013; 45:2121-2129.

29. Wollersheim T, Woehlecke J, Krebs M, Hamati J, Lodka D, LutherSchroeder A, Langhans C, Haas K, Radtke T, Kleber C, et al. Dynamics of myosin degradation in intensive care unit-acquired weakness during severe critical illness. Intensive Care Med 2014;40: 528-538.

30. Klaude M, Fredriksson K, Tjäder I, Hammarqvist F, AhIman B, Rooyackers O, Wernerman J. Proteasome proteolytic activity in skeletal muscle is increased in patients with sepsis. Clin Sci (Lond) 2007;112:499-506.

31. Klaude M, Mori M, Tjäder I, Gustafsson T, Wernerman J, Rooyackers O. Protein metabolism and gene expression in skeletal muscle of critically ill patients with sepsis. Clin Sci (Lond) 2012;122:133-142.

32. Derde S, Hermans G, Derese I, Güiza F, Hedström Y, Wouters PJ, Bruyninckx F, D'Hoore A, Larsson L, Van den Berghe G, et al. Muscle atrophy and preferential loss of myosin in prolonged critically ill patients. Crit Care Med 2012;40:79-89.

33. Constantin D, McCullough J, Mahajan RP, Greenhaff PL. Novel events in the molecular regulation of muscle mass in critically ill patients. J Physiol 2011;589:3883-3895.

34. Hussain SN, Mofarrahi M, Sigala I, Kim HC, Vassilakopoulos T, Maltais F, Bellenis I, Chaturvedi R, Gottfried SB, Metrakos P, et al. Mechanical ventilation-induced diaphragm disuse in humans triggers autophagy. Am J Respir Crit Care Med 2010;182:1377-1386.

35. Vanhorebeek I, Gunst J, Derde S, Derese I, Boussemaere M, Güiza F, Martinet W, Timmermans JP, D'Hoore A, Wouters PJ, et al. Insufficient activation of autophagy allows cellular damage to accumulate in critically ill patients. J Clin Endocrinol Metab 2011;96: E633-E645.

36. Stevens JE, Walter GA, Okereke E, Scarborough MT, Esterhai JL, George SZ, Kelley MJ, Tillman SM, Gibbs JD, Elliott MA, et al. Muscle adaptations with immobilization and rehabilitation after ankle fracture. Med Sci Sports Exerc 2004;36:1695-1701.

37. Milsom J, Barreira P, Burgess DJ, Iqbal Z, Morton JP. Case study: Muscle atrophy and hypertrophy in a premier league soccer player during rehabilitation from ACL injury. Int $J$ Sport Nutr Exerc Metab 2014;24:543-552.

38. Rutherford OM, Jones DA, Round JM. Long-lasting unilateral muscle wasting and weakness following injury and immobilisation. Scand $J$ Rehabil Med 1990;22:33-37.

39. Walsh CJ, Batt J, Herridge MS, Dos Santos CC. Muscle wasting and early mobilization in acute respiratory distress syndrome. Clin Chest Med 2014;35:811-826.

40. Montarras D, L'honoré A, Buckingham M. Lying low but ready for action: the quiescent muscle satellite cell. FEBS J 2013;280: 4036-4050.
41. Jackson JR, Mula J, Kirby TJ, Fry CS, Lee JD, Ubele MF, Campbell KS, McCarthy JJ, Peterson CA, Dupont-Versteegden EE. Satellite cell depletion does not inhibit adult skeletal muscle regrowth following unloading-induced atrophy. Am J Physiol Cell Physiol 2012;303: C854-C861.

42. Lepper C, Partridge TA, Fan CM. An absolute requirement for Pax7positive satellite cells in acute injury-induced skeletal muscle regeneration. Development 2011;138:3639-3646.

43. Murphy MM, Lawson JA, Mathew SJ, Hutcheson DA, Kardon G. Satellite cells, connective tissue fibroblasts and their interactions are crucial for muscle regeneration. Development 2011;138:3625-3637.

44. Sambasivan R, Yao R, Kissenpfennig A, Van Wittenberghe L, Paldi A, Gayraud-Morel B, Guenou H, Malissen B, Tajbakhsh S, Galy A. Pax7-expressing satellite cells are indispensable for adult skeletal muscle regeneration. Development 2011;138:3647-3656.

45. Kadi F, Charifi N, Denis C, Lexell J. Satellite cells and myonuclei in young and elderly women and men. Muscle Nerve 2004;29:120-127.

46. Christov C, Chrétien F, Abou-Khalil R, Bassez G, Vallet G, Authier FJ, Bassaglia Y, Shinin V, Tajbakhsh S, Chazaud B, et al. Muscle satellite cells and endothelial cells: close neighbors and privileged partners. Mol Biol Cell 2007;18:1397-1409.

47. Romanello V, Sandri M. Mitochondrial biogenesis and fragmentation as regulators of muscle protein degradation. Curr Hypertens Rep 2010; 12:433-439.

48. Carré JE, Orban JC, Re L, Felsmann K, Iffert W, Bauer M, Suliman HB, Piantadosi CA, Mayhew TM, Breen P, et al. Survival in critical illness is associated with early activation of mitochondrial biogenesis. Am J Respir Crit Care Med 2010;182:745-751.

49. Lehnart SE. Novel targets for treating heart and muscle disease: stabilizing ryanodine receptors and preventing intracellular calcium leak. Curr Opin Pharmacol 2007;7:225-232.

50. Hairi NN, Cumming RG, Naganathan V, Handelsman DJ, Le Couteur DG, Creasey H, Waite LM, Seibel MJ, Sambrook PN. Loss of muscle strength, mass (sarcopenia), and quality (specific force) and its relationship with functional limitation and physical disability: the Concord Health and Ageing in Men Project. J Am Geriatr Soc 2010; 58:2055-2062.

51. Reid MB, Moylan JS. Beyond atrophy: redox mechanisms of muscle dysfunction in chronic inflammatory disease. J Physiol 2011;589: 2171-2179.

52. Gosselink R, Troosters T, Decramer M. Peripheral muscle weakness contributes to exercise limitation in COPD. Am J Respir Crit Care Med 1996;153:976-980.

53. Harbo T, Brincks $\mathrm{J}$, Andersen $\mathrm{H}$. Maximal isokinetic and isometric muscle strength of major muscle groups related to age, body mass, height, and sex in 178 healthy subjects. Eur J Appl Physiol 2012;112:267-275. 